\title{
INFLUENCE OF TEMPORAL BASELINE ON THE VERTICAL ABSOLUTE ACCURACIES OF TSX HS INTERFEROMETRIC DSMS: CASE STUDY ON BERLIN
}

\author{
Umut G. Sefercik ${ }^{1}$, Uwe Soergel ${ }^{2}$ \\ ${ }^{1}$ Bulent Ecevit University, Department of Geomatics Engineering, Zonguldak, Turkey - \\ ugsefercik@hotmail.com \\ ${ }^{2}$ Institute of Geodesy, Technical University Darmstadt, Darmstadt, Germany - \\ soergel@geod.tu-darmstadt.de
}

\section{Commission VII, WG VII/2}

Key Words: Temporal baseline, SAR, TSX, DSM, Accuracy

\begin{abstract}
:
In recent years, interferometric sytnthetic aperture radar (InSAR) is one of the most preferred techniques to generate digital surface models (DSM) which are the three dimensional (3D) digital cartographic representations of earth surface including all terrain and non-terrain formations. Interferometric DSM generation using synthetic aperture radar (SAR) imagery is not an easy process and the vertical absolute accuracy of the final product depends on various parameters. In this study, we aimed to demonstrate the influence of temporal baseline between SAR image-pairs on the vertical absolute accuracy of high resolution interferometric DSMs. The application was realized covering $20 \mathrm{~km}^{2}$ area in Berlin, Germany using 15 descending orbit high resolution spotlight (HS) TerraSAR-X (TSX) images. The suitable interferometric pairs were determined for DSM generation and two of them that have similar parameters except temporal baseline were selected regarding the purposes of the study. The master image was selected as same in the generation of both DSMs and the temporal baselines between this master image and slave images were 11 days (1 period) and 187 days (17 periods), respectively. TSX HS DSMs were generated with $2 \mathrm{~m}$ grid spacing and the vertical absolute accuracies were calculated based on the comparison with a reference DSM generated by radargrammetry. The analyses were realized for built-up and forest land classes separately. The results proved that longer temporal baseline has negative influence on the vertical absolute accuracies of TSX HS interferometric DSMs. The first DSM which has the shortest temporal baseline, possible for TSX sensing is better than the second one as approx. $1.5 \mathrm{~m}$ both for built-up and forest areas.
\end{abstract}

\section{INTRODUCTION}

A digital surface model (DSM) represents the visual top surfaces of all terrain and non-terrain formations from bird eye's view with $\mathrm{X}$ and $\mathrm{Y}$ planimetric coordinates and elevation Z. DSM is the first three dimensional (3D) model provided by remote sensing systems and digital elevation models (DEMs) and digital terrain models (DTMs) including bare ground are achieved by filtering it. DSMs are constantly used by different occupational branches such as mapping, disaster monitoring and management, geographic information systems (GIS), forestry, and agriculture that's why several DSM generation techniques have been improved up to date (Thompson et al., 2001; Vassilopoulou et al., 2002; Fraser, 2003; Schmidt and Persson, 2003; Navalgund et al., 2007; Font et al., 2010; Sterenczak and Kozak, 2011). One of the most preferred techniques for DSM generation from space-borne data is interferometric synthetic aperture radar (InSAR). In this technique, the DSM is created with a mathematical model using the geometrical parameters of an InSAR-pair. This pair can be achieved by single-pass or repeat-pass of a synthetic aperture radar (SAR) satellite sensor covering a selected study area. In single-pass, transmitter and receiver SAR antennas are located on the spacecraft with a short distance as available in shuttle radar topography mission (SRTM) thus the data of an area is collected simultaneously from slightly different looking angles (Rabus et al, 2003). In this wise, SAR signals follow very similar ways in the atmosphere and atmospheric de-correlation is not the case. However, single-pass is not a frequently used geometry because of limitations based on short baseline between antenna positions (60m for SRTM). Today, these limitations are tried to overcome with operating TerraSAR-X (TSX) and TanDEM-X (TDX) satellites simultaneously with a pre-determined baseline between their SAR antennas (Soergel et al., 2013). The large portion of interferometric DSMs are generated with the data derived from repeat-pass technique that includes a temporal baseline between two positions of a SAR antenna. In addition, displacement maps, that represent the 3D surface deformations, are generated based on multi-temporal SAR images (Ferretti et al., 1999; Wdowinski et al., 2009; Jung and Alsdorf, 2010). While providing useful data for many applications, temporal baseline may cause reduction of coherence between InSAR-pair depending on atmospheric decorrelation because of seasonal effects (water vapor, rainfall, wind etc.) (Lau et al., 2005). Although, several multi-temporal SAR imagery based studies exist, the loss of vertical accuracy attached to temporal baseline were not be debated in the literature.

The aim of this paper is to prove the adverse effect of temporal baseline on the vertical accuracy of interferometric DSMs with a sample survey. In the application, two different interferometric DSMs were generated from suitable TSX high resolution spotlight (HS) InSAR-pairs having 11 days and 187 
days temporal baseline covering Berlin, Germany and the vertical accuracies of these DSMs were validated based on comparison with a reference DSM derived from radargrammetry.

The paper is organized as follows; information about the study area and used materials is given in section 2. The methodology of DSM generation and vertical accuracy calculation is explained in section 3. Next, the achieved results are shown in section 4 followed by the conclusions of the paper.

\section{STUDY AREA AND MATERIALS}

Berlin is one of the 16 states and the capital city of Germany having 3.4 million population. In the city, $5 \times 4 \mathrm{~km}\left(20 \mathrm{~km}^{2}\right)$ common area was determined considering the borders of available TSX HS images and the reference DSM generated by Joanneum Research (Fig. 1). The area is dominated with builtup and forest land classes and the elevation changes between sea level and $200 \mathrm{~m}$.

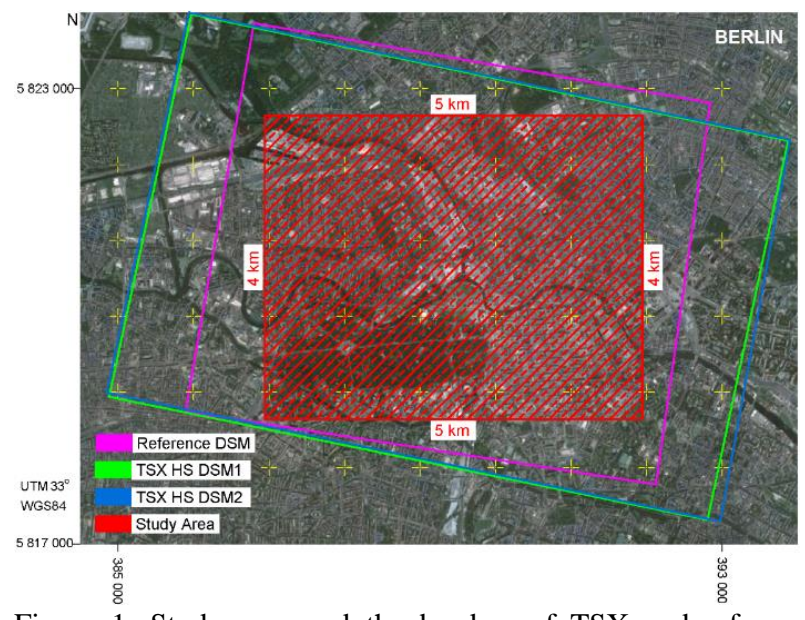

Figure 1. Study area and the borders of TSX and reference DSMs

Berlin was preferred as the study area for this research because of having large urban area and several available TSX HS images achieved within the scope of Multilateral TSX project (LAN0634) supported by German Aerospace Center (DLR). In the city, 25 ascending and 15 descending orbit TSX HS SAR images exist in the beams of SPOT028A and SPOT042D respectively. The study was realized using 15 descending orbit images. The repeat-cycle of TSX satellite is 11 days that corresponds the minimum temporal baseline between TSX InSAR-pairs. As a consequence, first InSAR-pair was decided to prefer through the pairs that have 11 days (1 period) temporal baseline. To show the influence of seasonal effects on the vertical accuracy of DSMs most clearly, in the selection of second pair, the main criteria was approx. six months temporal baseline ( $\approx 16$ periods) from same master image. To determine the optimal InSAR-pairs consistent with the objectives of the research, all candidate pairs were co-registered and baseline parameters were estimated separately. While selecting the optimal InSAR-pairs, we paid attention to similar baseline parameters except temporal baseline. In this manner, the effect of temporal baseline can be appeared more clearly. In addition to beams and orbits, polarization modes of used images are same and the average incidence angles are very similar. Thus, the factors of multi-looking, used for speckle noise filtering, were selected as same while generating interferograms. Table 1 shows the selected InSAR-pairs and estimated baseline parameters.

Table 1. Specifications and estimated baseline parameters of selected InSAR-pairs

\begin{tabular}{|c|c|c|c|c|}
\hline \multirow{2}{*}{ Parameters } & \multicolumn{2}{|c|}{ InSAR-pair 1} & \multicolumn{2}{|c|}{ InSAR-pair 2} \\
\hline & Image 4 & Image 5 & Image 4 & Image 12 \\
\hline $\begin{array}{l}\text { Imaging } \\
\text { Mode }\end{array}$ & \multicolumn{4}{|c|}{ HS } \\
\hline $\begin{array}{l}\text { Acquisition } \\
\text { time }\end{array}$ & $10 / 05 / 08$ & $21 / 05 / 08$ & $10 / 05 / 08$ & $13 / 11 / 08$ \\
\hline Pixel spacing & 0.8713 & 0.8713 & 0.8713 & 0.8713 \\
\hline $\mathrm{Az} / \mathrm{Rg}$ & 0.7720 & 0.7719 & 0.7720 & 0.7720 \\
\hline Beam ID & \multicolumn{4}{|c|}{ Spot 042D } \\
\hline Orbit & \multicolumn{4}{|c|}{ Descending } \\
\hline Polarization & \multicolumn{4}{|c|}{ Single - VV } \\
\hline $\begin{array}{l}\text { Incidence } \\
\text { angle }\left(^{\circ}\right)\end{array}$ & 36.0854 & 36.0903 & 36.0854 & 36.0874 \\
\hline $\begin{array}{l}\text { Temporal } \\
\text { baseline }\end{array}$ & \multicolumn{2}{|c|}{11 days ( 1 period) } & \multicolumn{2}{|c|}{187 days (17 periods) } \\
\hline $\begin{array}{l}\text { Normal } \\
\text { baseline (m) }\end{array}$ & \multicolumn{2}{|c|}{246.924} & \multicolumn{2}{|c|}{221.403} \\
\hline $\begin{array}{l}\text { Critical } \\
\text { baseline }(\mathrm{m})\end{array}$ & \multicolumn{2}{|c|}{12628.805} & \multicolumn{2}{|c|}{12628.805} \\
\hline $\begin{array}{l}2 \pi \text { ambiguity } \\
\text { height }(\mathrm{m})\end{array}$ & \multicolumn{2}{|c|}{23.177} & \multicolumn{2}{|c|}{25.849} \\
\hline $\begin{array}{l}\mathrm{Rg} \text { and } \mathrm{Az} \\
\text { shift (pixel) }\end{array}$ & \multicolumn{2}{|c|}{$426.349 /-38.348$} & \multicolumn{2}{|c|}{$347.033 / 33.599$} \\
\hline $\begin{array}{l}\text { Doppler } \\
\text { centroid dif. } \\
(\mathrm{Hz})\end{array}$ & \multicolumn{2}{|c|}{83.548} & \multicolumn{2}{|c|}{67.191} \\
\hline
\end{tabular}

\section{METHODOLOGY}

The methodology of the study can be separated to two main stages as the generation of interferometric DSMs and vertical accuracy assessment. In first stage, following standard DSM generation procedures were completed using SarScape 4.3 module under ENVI 4.8. First, all of the candidate InSAR-pairs were co-registered and baseline parameters were estimated. After determining optimal pairs, interferograms were generated (Fig. 2). As known, signal to noise ratio (SNR) is one of the most crucial components that directly affects the quality of final interferometric products. As a consequence, noise reduction was performed by averaging the neighboring pixels of the complex interferogram generating square pixels, with the cost of lowering its spatial resolution by multi-looking (Manjunath, 2008). Considering range and azimuth resolutions and incidence angles of used images and the aimed pixel spacing of final DSM, multi-looking factors of $2 \times 2$ for range and azimuth were applied respectively. After interferogram generation, several low-frequency components were removed by flattening calculating the differential phase between the constant phase and the phase expected for flat or known topography. Both for interferogram generation and flattening, to provide basic cartographic system, SRTM3 version 4 DSM of the study area was employed. In the next step, available noise caused by temporal or baseline related de-correlation was reduced by Goldstein filtering algorithm (Goldstein and Werner, 1998). Coherence maps that shows the low and high coherent parts of master and slave images were created (Fig. 3) and phase unwrapping was completed utilizing regional growing algorithm (Reigber and Moreira, 1997). For geometric correction through orbital refinement, ground control points (GCPs) were collected on flattened interferogram using coherence maps (Fig. 3). And finally, DSMs were obtained (Fig. 5) by conversion of phase to height and geocoding process. The DSMs were generated with 
$2 \mathrm{~m}$ grid spacing considering $2 \mathrm{~m}$ gridded reference DSM. The generated DSMs from InSAR-pair 1 and 2 were named as TSX DSM 1 and TSX DSM 2, respectively.

In the study, the absolute and relative vertical accuracies of DSMs were described with standard deviation of height discrepancies $\left(\sigma_{\Delta g}\right)$ between tested TSX models and reference radargrammetric (REFRAD) model. The $\sigma_{\Delta z}$ was calculated with the basic equ. [1]; where $\mu$ is the arithmetic mean of $\Delta Z$. In absolute vertical accuracy (AVA) calculation, the effect of terrain slope $(\alpha)$ was also calculated and added to the certain $\sigma_{\Delta z}$ value with multiplying factor of $b$. The AVAs of DSMs were calculated with following equ. [2].

$\sigma_{\Delta Z}=\sqrt{\frac{\sum_{i=1}^{n}\left(\Delta Z_{i}-\mu\right)^{2}}{n-1}}$

$$
A V A=\sigma_{\Delta Z}+b \times \tan (\alpha)
$$

Relative vertical accuracy (RVA) is very significant component to exhibit the adverse effect of temporal baseline on the interior homogeneity of a DSM. Interior homogeneity was calculated based on the relationship between the neighbouring pixels. The previously contributions prove that the RVAs of interferometric DSMs are superior to their AVAs (Jacobsen, 2003, 2012). The RVAs of the DSMs were calculated based on equ. [3]; where $D$ is the distance between pixels, $D_{l}$ and $D_{u}$ are the lower and upper distance limits. For each pixel, the neighbouring 10 pixels were used to calculate the RVAs based on $\Delta Z$ from the REFRAD. That means, $D$ is between $2 m$ to $20 m$ for $1^{s t}$ to $10^{\text {th }}$ neighbouring pixels.

$$
R V A=\sqrt{\frac{\sum\left(D z_{i}-D z_{j}\right)^{2}}{(2 \times n z)}}, D_{\mathbb{l}}<D<D_{u}
$$

\section{RESULTS}

Figure $2 \mathrm{a}$ and $2 \mathrm{~b}$ shows the generated interferograms from InSAR-pair 1 and 2 respectively applying the multi-looking factors of $2 \times 2$ for azimuth and range directions. Although having same azimuth and range resolutions, similar incidence angles and baseline parameters except temporal baseline, interferogram of TSX InSAR-pair 2 has more noisy view in comparison with the interferogram of TSX InSAR-pair 1.

The created coherence maps and the location of collected GCPs are shown in Figure $3 \mathrm{a}$ and $3 \mathrm{~b}$. For the collection of GCPs, spatial profiles were plotted on the coherence maps and the areas that have high coherence $(\geq 0.8)$ and not affected by layover were preferred.

The coherence distribution of InSAR-pairs are displayed in Figure 4. It is clear that InSAR-pair 1 (red) with 1 period temporal baseline has more points that have more than 0.5 coherence against InSAR-pair 2.

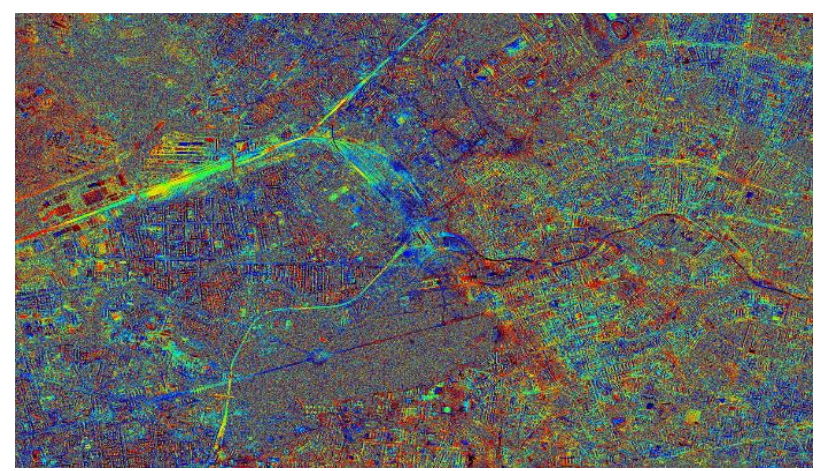

a

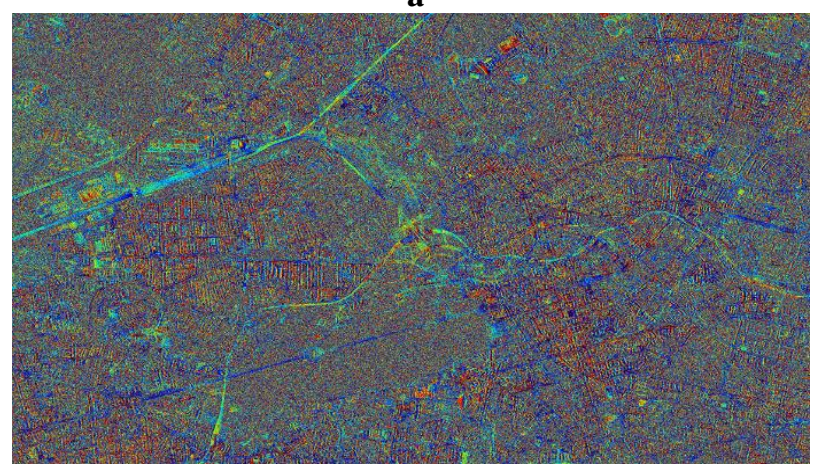

b

Figure 2. Generated Interferograms $(\mathrm{a}=$ InSAR-pair 1, b= InSAR-pair 2)

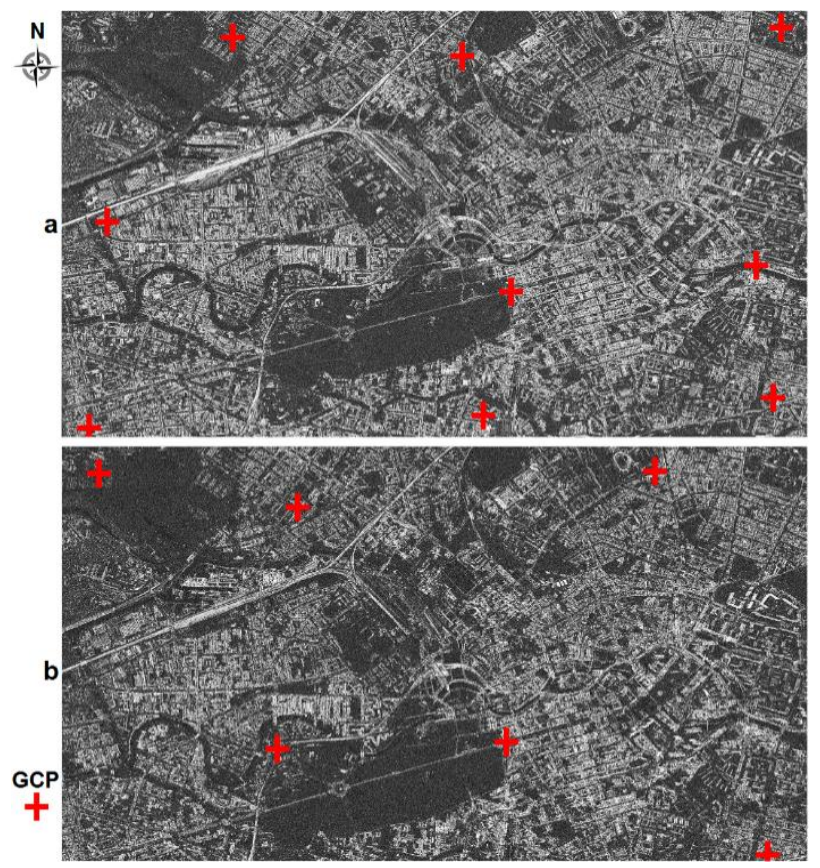

Figure 3. Coherence maps and GCP distributions ( $a=$ InSAR-pair 1, b= InSAR-pair 2) 


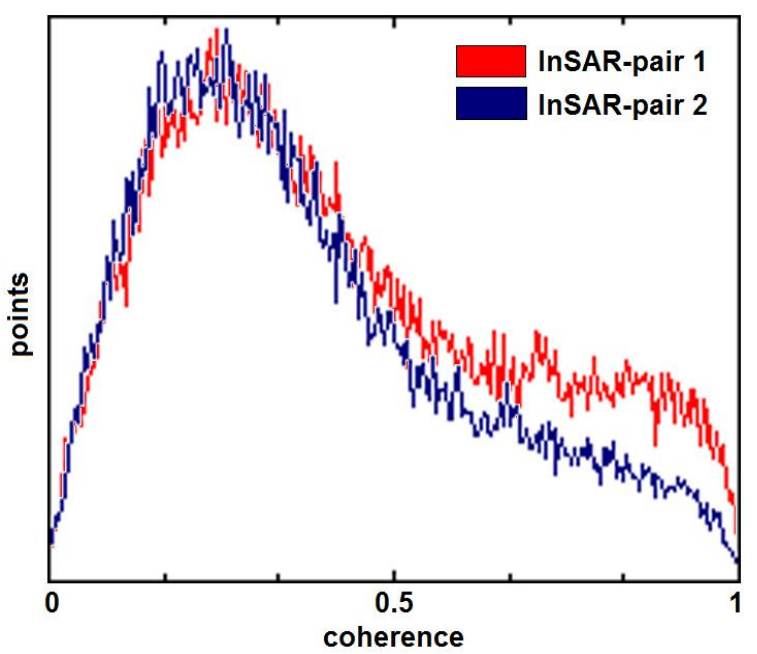

Figure 4. Coherence of InSAR-pairs

The generated interferometric DSMs in UTM $33^{\circ}$ WGS84 are shown in Figure $5 \mathrm{a}$ and $5 \mathrm{~b}$. Considering terrain and non-terrain formations, it is easily seen that the representation performance of DSM 1 are superior to DSM 2.
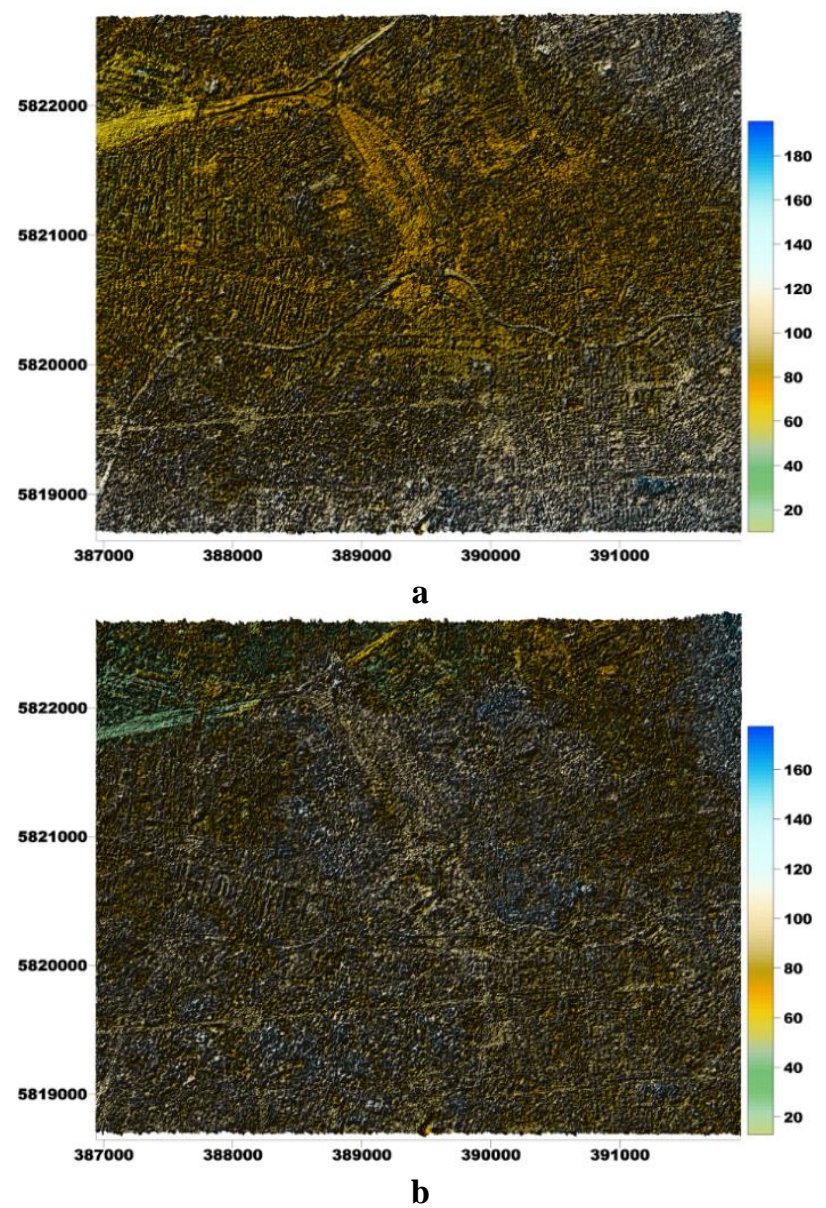

Figure 5. Generated DSMs (a= DSM 1, b= DSM 2)

To achieve $100 \%$ successful vertical accuracy assessment the horizontal offsets between tested DSMs and REFRAD were calculated and eliminated with horizontal shifting based on cross correlation. Table 2 shows the eliminated horizontal offsets in X and Y directions separately.
Table 2. Eliminated horizontal offsets

\begin{tabular}{cccc}
\hline $\begin{array}{c}\text { Reference } \\
\text { model }\end{array}$ & $\begin{array}{c}\text { Tested } \\
\text { model }\end{array}$ & DX $(\mathbf{c m})$ & DY $(\mathbf{c m})$ \\
\hline \multirow{2}{*}{ REFRAD } & DSM1 & -13 & 3.5 \\
& DSM2 & -15 & -11 \\
\hline
\end{tabular}

Table 3 shows the AVAs of generated DSMs based on 5 million compared pixels with REFRAD. In comparison, maximum accepted $\Delta Z$ between tested models and REFRAD was selected as $35 \mathrm{~m}$ and the points that exceed this threshold were excluded in the calculation. The AVA of DSM 1 is approx. $1.5 \mathrm{~m}$ better than DSM 2 both for built-up and forest areas.

Table 3. AVAs of TSX DSMs ( $\alpha=$ terrain slope, $E P=$ excluded points)

\begin{tabular}{|c|c|c|c|c|}
\hline $\begin{array}{c}\text { Reference } \\
\text { DSM }\end{array}$ & $\begin{array}{l}\text { Tested } \\
\text { DSM }\end{array}$ & Land class & $\sigma_{Z}(\mathbf{m})$ & $\begin{array}{c}E P \\
(\%)\end{array}$ \\
\hline \multirow{12}{*}{ REFRAD } & \multirow{6}{*}{ DSM1 } & \multirow{2}{*}{$\begin{array}{c}\text { whole area } \\
(100 \%)\end{array}$} & 10.74 & 0.18 \\
\hline & & & $9.31+8.88 \times \tan (\alpha)$ & 0.10 \\
\hline & & \multirow{2}{*}{$\begin{array}{l}\text { built-up } \\
(84.94 \%)\end{array}$} & 11.11 & 0.21 \\
\hline & & & $9.45+11.19 \times \tan (\alpha)$ & 0.14 \\
\hline & & \multirow{2}{*}{$\begin{array}{c}\text { forest } \\
(15.06 \%)\end{array}$} & $9.04+0.36 \times \tan (\alpha)$ & 0.03 \\
\hline & & & $8.63+0.59 \times \tan (\alpha)$ & 0.01 \\
\hline & \multirow{6}{*}{ DSM2 } & \multirow{2}{*}{$\begin{array}{c}\text { whole area } \\
(100 \%)\end{array}$} & 12.54 & 0.63 \\
\hline & & & 11.22 & 0.13 \\
\hline & & \multirow{2}{*}{$\begin{array}{l}\text { built-up } \\
\text { (84.94\%) }\end{array}$} & 13.05 & 0.70 \\
\hline & & & 11.42 & 0.18 \\
\hline & & \multirow{2}{*}{$\begin{array}{c}\text { forest } \\
(15.06 \%)\end{array}$} & 10.36 & 0.31 \\
\hline & & & 9.98 & $\mathbf{0 . 0 3}$ \\
\hline
\end{tabular}

The distribution of $\Delta Z$ separately for built-up and forest areas are shown in Figure 6a and 6b. The red lines describe the zero $\Delta Z$. In DSM 1, the peak of $\Delta Z$ locates on zero and the distribution is nearly symmetric. On the other hand, the peak of $\Delta Z$ is more than $5 \mathrm{~m}$ in DSM 2. Considering forest areas, the peak of distribution both in DSM 1 and 2 is around $5 \mathrm{~m}$. While the distribution in DSM 1 is totally symmetric, DSM 2 has a fluctuation between $15 \mathrm{~m}$ and $25 \mathrm{~m}$.

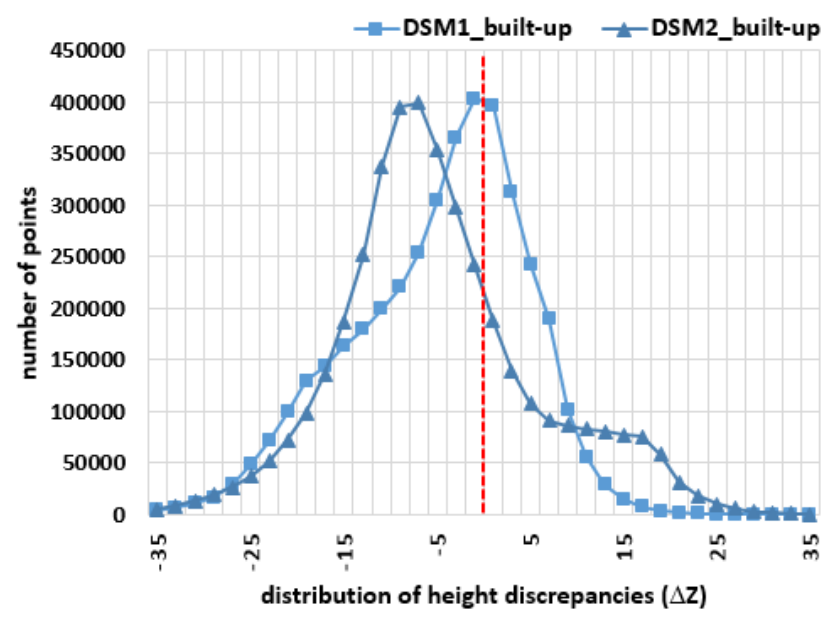

a 


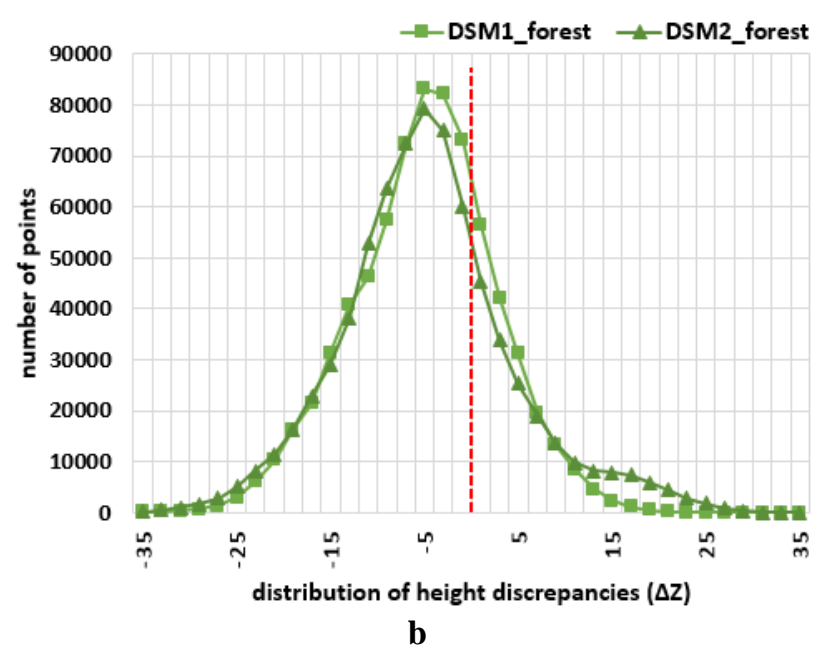

Figure 6. Distribution of height discrepancies ( $\mathrm{a}=$ built-up, $\mathrm{b}=$ forest)

The RVAs of DSMs in built-up and forest areas are illustrated in Figure 7. Although they have similar trends, the RVAs in DSM 1 is superior to DSM 2 both for built-up and forest areas. As expected, the RVAs of both DSMs are better than their AVAs.

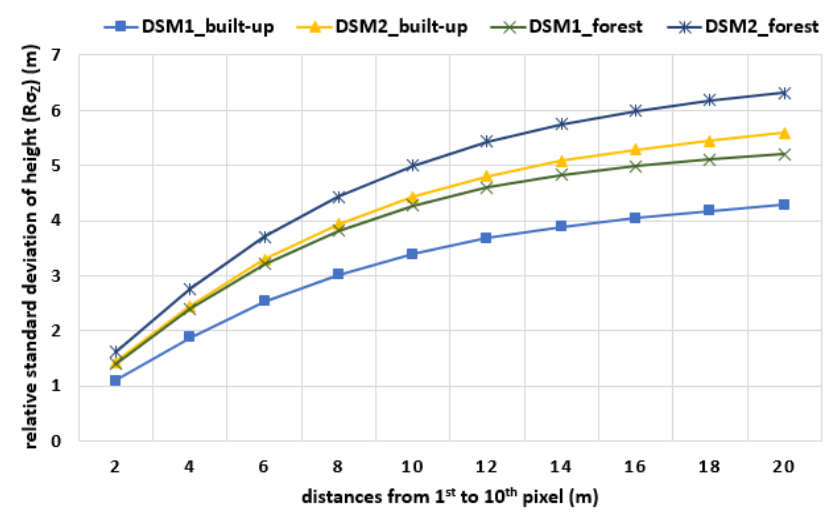

Figure 7. RVAs of generated DSMs

As mentioned before, the specifications and the baseline parameters of used InSAR-pairs are nearly the same except temporal baseline. This point proves that the main cause of accuracy differences between DSM 1 and 2 can be described with seasonal effects because of temporal baseline which might be as important as the imaging geometry for the generation of coherence (Lau et al., 2005).

\section{CONCLUSION}

In this paper, the influence of temporal baseline on the vertical accuracy of interferometric DSMs derived from TSX HS InSAR-pairs was investigated. Berlin was selected as the study area because of having large urban area and data availability. In the application, two InSAR-pairs were selected between 15 descending orbit TSX HS images and the temporal baselines of first and second InSAR-pair were 11 days (1 period) and 187 days (17 periods) respectively. The absolute and relative vertical accuracies of generated DSMs were calculated based on comparison with a reference radargrammetric DSM created by Joanneum research. The absolute standard deviation of DSM 1 derived from InSAR-pair 1 is approx. $1.5 \mathrm{~m}$ better than DSM 2, generated from InSAR-pair 2 both for built-up and forest areas.
In addition, the interior homogeneity of DSM 1 is superior to DSM 2 likewise absolute vertical accuracies. These results demonstrated that temporal baseline has a significant influence on the vertical accuracies of interferometric DSMs.

\section{ACKNOWLEGMENTS}

Thanks are going to DLR (German Aerospace Center), Germany, for providing about TSX images without any cost in the framework of the project LAN0634.

\section{REFERENCES}

Ferretti, A., Prati, C., Rocca, F. 1999. Monitoring terrain deformations using multi-temporal SAR images, Proceedings of Fringe'99, Liege, Belgium, November 1999.

Font, M., Amorese, D., Lagarde, J. L. 2010. DEM and GIS analysis of the stream gradient index to evaluate effects of tectonics: the Normandy intraplate area (NW France). Geomorphology, 119(3-4): 172-180.

Fraser, C. S., 2003. Prospects for mapping from high-resolution satellite imagery. Asian Journal of Geoinformatics, 4(1): 3-10.

Goldstein, R. M., Werner, C. L. 1998. Radar interferogram filtering for geophysical applications. Geophysical Research Letters, 25(21), 4035-4038.

Jacobsen, K. 2003. DEM Generation from Satellite Data. EARSeL Workshop, 5-7 June, Ghent, Belgium, pp. 273-276.

Jacobsen, K. 2005. Analysis of SRTM Elevation Models, EARSeL 3D-Remote Sensing Workshop, Porto, on CD.

Jung, H., Alsdorf, D. 2010. Repeat-pass multi-temporal interferometric SAR coherence variations with Amazon floodplain and lake habitats, International Journal of Remote Sensing, Vol. 31, No. 4, pp. 881-901.

Lau, W.Y., Meng, D., Chang, H.C., Ge, L., Jia, X., Lee, I. 2005. Seasonal Effect on InSAR DEMs. International Symposium on GPS/GNSS, Hong Kong, 8-10 December, paper 10A-02, on CD.

Manjunath, D. 2008. Earthquake interaction along the Sultandagi-Aksehir fault based on InSAR and Coulomb stress modeling. University of Missouri, Columbia, PhD Thesis, 65p.

Navalgund, R. R., Jayaraman, V., Roy, P. S. 2007. Remote sensing applications: an overview. Current Science, 93(12): 1747-1766.

Rabus, B., Eineder, M., Roth, A., Bamler, R. 2003. The shuttle radar topography mission - a new class of digital elevation models acquired by spaceborne radar. ISPRS Journal of Photogrammetry \& Remote Sensing, 57(4), 241-262.

Reigber, A., Moreira, J. 1997. Phase unwrapping by fusion of local and globalmethods. geoscience and remote sensing., Proceedings of IGARSS'97, Singapour, 3-8 August 1997, pp. 869-871. 
Schmidt, F. Persson, A. 2003. Comparison of DEM data capture and topographic wetness indices. Precision Agriculture, 4(2): 179-192.

Wdowinski, S., Hong, S. H., Kim, S. W., Won, J. S. 2010. Small Temporal Baseline Subset Analysis (Stbas): An Insar Technique for Multi-Temporal Water Level Monitoring In Wetlands, Proceedings of 'Fringe 2009 Workshop', Frascati, Italy, 30 November - 4 December 2009.

Soergel, U., Jacobsen, K., Schack, L. 2013. The TanDEM-X Mission: Data Collection and Deliverables, Photogrammetric week 2013, Dieter Fritsch (Ed.), pp.193-203.

Sterenczak, K. Kozak, J. 2011. Evaluation of digital terrain models generated in forest conditions from airborne laser scanning data acquired in two seasons. Scandinavian Journal of Forest Research, 26(4): 374-384.

Thompson, J. A., Bell, J. C., Butler, C. A. 2001. Digital elevation model resolution: effects on terrain attribute calculation and quantitative soil-landscape modeling. Geoderma, 100(1-2): 67-89.

Vassilopoulou, S., Hurni, L., Dietrich, V., Baltsavias, E., Pateraki, M., Lagios, E. Parcharidis, I. 2002. Orthophoto generation using IKONOS imagery and high-resolution DEM: a case study on volcanic hazard monitoring of Nisyros Island (Greece), ISPRS Journal of Photogrammetry and Remote Sensing, 57(1-2): 24-38. 